\title{
Type 2 Diabetes Mellitus And Vitamin C
}

\author{
Shabzain Ishrat, Talea Hoor, Mohammed Sajid Abbas Jaffri
}

- - - - - - - - - - - - - - - - - - - - - - - - - - - - - ABSTRACT:

Type 2 diabetes mellitus (DM) is a chronic disease which deteriorates the quality of life with time. Type 2 DM accounts for more than $90 \%$ cases of diabetes mellitus as compared to other types of this disease. There is significant oxidative stress in type $2 \mathrm{DM}$ which plays an important role in the pathogenesis of disease. In order to combat this oxidative stress antioxidant supplements have to be added as add on therapy along with treatment of type $2 \mathrm{DM}$. Vitamin $\mathrm{C}$ is the safest antioxidant which plays significant role in diminishing the oxidative stress. The vitamin $\mathrm{C}$ supplementation have good control of FBS and $\mathrm{HbA} 1 \mathrm{c}$ and therefore helps in achieving better glycemic control along with prevention of lipid abnormalities.

Keywords: fasting blood sugar, glycosylated hemoglobin, glycemic control, type 2 diabetes mellitus, vitamin $\mathrm{C}$,

\section{INTRODUCTION:}

Diabetes mellitus (DM) is one of the chronic disease which is characterized by several metabolic abnormalities including hyperglycemia. The complicated type 2 diabetes mellitus has increased morbidity and mortality. ${ }^{1}$ People who are genetically prone for disease will tend to have the disease early in life. Similarly lifestyle and environment also has an important role in disease causation. ${ }^{2}$ This disease is continuously rising and will raise the figure in near future. The current prevalence of DM is $8.7 \%$ worldwide. ${ }^{3}$ Approximately 366 million people will be affected by the end of year 2030. ${ }^{4}$ According to the statistics of World health organization type 2 diabetes mellitus will be among the top ten leading causes of mortality by the year 2030..$^{5}$ In 2015 about 5 million deaths were caused by diabetes mellitus. This number shows that in every six seconds a person dies due to complicated diabetes mellitus. Half of the population remains un-diagnosed equivalent to one in two persons. In Pakistan the disease is also much prevalent about $11.7 \%$. The disease has predilection for male and urban area population as compared to female and rural area population. They tend to consume more and advanced calorie food and have stressful daily routine. ${ }^{6}$ Type $2 \mathrm{DM}$ has increased levels of free radicals which are generated in response to increased oxidative stress. Among them reactive oxygen species have an important role in disease pathogenesis. This disease also affects different sites and organs across the body and the smaller and larger vessels are afflicted more which leads to

I Shabzain Ishrat
M.phil Student Pharmacology,
Bahria University Medical and Dental College, Karachi
I Email: ishabzain@hotmail.com
I Talea Hoor
I Professor of Pharmacology,
| Bahria University Medical and Dental College, Karachi
I Mohammed Sajid Abbas Jaffri
I Professor of Medicine,
| Bahria University Medical and Dental College, Karachi
| Received: 06-02-2019
I Accepted: 14-05-2019

micro-vascular and macro-vascular complications respectively. These complications are enhanced and occur rapidly in the presence of free radicals which affect the cellular organelles and functions by changing the lipid protein ratio of membranes through lipid peroxidation. ${ }^{7}$ The oxidative stress in hyperglycemia is due to several pathways which include increased flow of glucose and other sugars by the polyol pathway activation which along with increased production of glycosylated products and their receptors for magnified actions to occur. Protein kinase isoforms are activated and hexosamine pathway also becomes overactive. ${ }^{8}$ The other pathways include glycosylation through nonenzymatic mechanisms. The status of anti-defense mechanisms, inflammatory mediators, sorbitol pathway and metabolic abnormalities has also been implicated in the disease pathogenesis. ${ }^{9}$ Despite the best available therapy of type 2 diabetes mellitus, it progresses ultimately and has poor outcome. Therefore researchers are continuously working to improve the disease outcome. Many antioxidants have been tested in type 2 diabetes mellitus. Vitamin $\mathrm{C}$ is one of the antioxidant which helps in controlling the oxidative damage and managing the hyperglycemia in a potent manner. ${ }^{10}$ People with type 2 diabetes mellitus have decreased levels of plasma vitamin $C$ which further aggravates the condition. ${ }^{11}$ In order to control the oxidative damage the researchers preferred antioxidant in the form of supplements for type 2 diabetic patients. Vitamin $\mathrm{C}$ diminishes oxidative damage caused by free radicals called reactive oxygen species and is the most important role of vitamin C. ${ }^{12}$ This can ultimately reduce the prevalence of diabetic complications and may help in achieving better outcome of the disease. ${ }^{13}$ In type 2 diabetic patients the lipid abnormalities also exist as there is dyslipidemia due to lipid peroxidation as a result of oxidative damage. Vitamin $\mathrm{C}$ can help in lowering the oxidative damage and thus can achieve good glycemic control and prevent the derangement of lipids. ${ }^{8}$

\section{METHODOLOGY:}

Pubmed, Cochrane library and Google scholar search engines were used to find the relevant studies for writing this review. 
The keywords used were vitamin C, type 2 diabetes mellitus, ascorbic acid, fasting blood sugar, HbA1c and glycemic control. The filter applied was of year duration between 2008 to 2018. The articles found were 123. From these 36 articles were not relevant, 5 articles were in non English language, 9 were animal studies, 11 were done in children, 10 showed only abstract, 8 were for gestational diabetes and 3 were type 2 diabetes with foot amputation. Finally 41 were selected for writing this review.

\section{REVIEW OF LITERATURE:}

Diabetes mellitus is one of the major endocrinopathy worldwide. It causes significant mortality and morbidity. ${ }^{14}$ The most prevalent type of diabetes mellitus is type $2 \mathrm{DM}$. Previously it was also known as non-insulin dependent diabetes mellitus. There is hyperglycemia along with abnormalities of insulin and relative insulin deficiency or insulin resistance. ${ }^{15}$

The most widely accepted classification is that of American Diabetes Association (ADA) according to which diabetes mellitus is classified into four types. These include type 1 DM, type $2 \mathrm{DM}$, gestational diabetes and some other types of diabetes mellitus. From these type 2 diabetes mellitus is the commonest and accounts for greater than $90 \%$ of cases. ${ }^{16}$

\section{Type 2 diabetes mellitus patho-physiology:}

The insulin abnormalities play an important role in the pathophysiology of diabetes mellitus. There are three main pathways which include insulin resistance, decreased synthesis of insulin and pancreatic beta cell failure. The catabolic pathways occur along with diminished uptake and transport of glucose. In previous studies it has also been implicated that the alpha cells not functioning properly also take part in the disease pathogenesis. As the time passes, the disease progresses to lifelong deteriorating complications and results in early morbidity and mortality.${ }^{15}$ Many diabetic individuals also suffers from lipid metabolic abnormalities. There is a triad of lipid abnormality found in these patients. It comprises of increased levels of triglycerides known as hypertriglyceridemia, low levels of high density lipoprotein cholesterol and increased levels of low density lipoprotein cholesterol. $^{17}$

\section{Oxidative stress in type 2 diabetes mellitus:}

Type $2 \mathrm{DM}$ is one of the chronic conditions in which body's antioxidant defense mechanisms does not function properly due to diminished levels of antioxidants. Free radicals are yielded in response to oxidative damage. These free radicals are called reactive oxygen species (ROS). Hyperglycemia induced glycation reaction leads to beta cell dysfunction and impairs the insulin production from beta cells hence causing hemoglobin glycosylation..$^{18}$ Complicated diabetes mellitus as a result of continuous oxidative stress causes six deaths in every minute. ${ }^{19}$ In the coming years this disease will become the most prevalent cause of preventable deaths. ${ }^{20}$
Mortality from CVS complications is also high in type 2 diabetic individuals. Lipid and lipoprotein abnormalities have been implicated in CVS complications. Hyperlipidemia in type 2 diabetes mellitus results from increased lipid peroxidation caused by free radicals generated in response to oxidative stress. ${ }^{14}$

\section{Vitamin $\mathrm{C}$ and insulin sensitivity in skeletal muscles:}

The greater portion of whole plasma glucose about $85-90 \%$ is distributed to skeletal muscles during hyperinsulinaemic and euglycemic states. The skeletal muscles are the main site of peripheral insulin resistance in type 2 diabetes mellitus. Skeletal muscles of type 2 diabetic patients are exposed to a greater deal of oxidative stress. Sodium dependent vitamin C transporters (SVCTs) help the vitamin C to be taken by most tissues. Of these SVCTs, only SVCT2 is found in skeletal muscles. This indicates that SVCT2 protein is required for uptake and storage of vitamin $\mathrm{C}$ in skeletal muscles. Vitamin C supplementation helps in diminishing the oxidative stress in skeletal muscles and promotes the insulin sensitivity that helps in glucose uptake. ${ }^{21}$

\section{Complications of diabetes mellitus:}

The complications of diabetes mellitus cause greater morbidity, mortality and disability. The complicated diabetes mellitus leads to significant damage and affects multiple organs and systems. They are classified into micro-vascular and macro-vascular. ${ }^{22}$

Smaller vessels are affected by these complications. Retina, kidney and nerves are the primary sites affected by these complications. Involvement of retinal vessels will lead to diabetic retinopathy while those of kidneys will lead to diabetic nephropathy and involvement of nerves will cause diabetic neuropathy. The risk factors that are proved to be predictive for micro-vascular complications include smoking, hypertension and duration of diabetes greater than 10 years. ${ }^{22}$

The complications which affect larger vessels involve the cardiovascular system and brain. Heart and peripheral vessels are most commonly involved and lead to coronary heart disease and peripheral arterial disease respectively while involvement of brain leads to stroke. Aging, male gender, smoking, sedentary lifestyle and high cholesterol are important risk factors for macro-vascular complications. ${ }^{22}$

Cardiovascular complications are more prevalent in type 2 diabetic individuals. There are about $80 \%$ chances of mortality due to CVS disease in diabetic patients. ${ }^{23}$

\section{Miscellaneous complications:}

Diabetic cardiomyopathy is a specific complication which develops independently of coronary artery disease or hypertension and leads to significant morbidity and mortality. ${ }^{22}$

\section{Diagnostic criteria of Diabetes mellitus:}

Certain parameters help in the diagnosis of diabetes mellitus. 
These include fasting blood sugar, oral glucose tolerance test, glycosylated hemoglobin and random plasma glucose. When fasting blood sugar levels are $=126 \mathrm{mg} / \mathrm{dl}(7.0$ $\mathrm{mmol} / \mathrm{L}$ ), plasma glucose after 2 hours of oral glucose tolerance test $=200 \mathrm{mg} / \mathrm{dl}(11.1 \mathrm{mmol} / \mathrm{L})$, or random plasma glucose values $=200 \mathrm{mg} / \mathrm{dl}(11.1 \mathrm{mmol} / \mathrm{L})$ with presence of symptoms of hyperglycemia will favor the diagnosis of diabetes mellitus. The glycosylated hemoglobin ( $\mathrm{HbA1c})$ also helps in diagnosing the disease if value is $=48 \mathrm{mmol} / \mathrm{L}$ (equivalent to $6.5 \%$ ). This criteria has been accepted internationally by different organizations and also by World Health Organization. ${ }^{24} \mathrm{HbA} 1 \mathrm{c}$ has been recommended for diagnostic purposes as well in addition monitoring treatment. This has been accepted by international committee of experts, ADA, the endocrine society, WHO, scientists and organizations all over the world. ${ }^{16}$

\section{Treatment choices:}

The treatment choices include oral and inject-able agents. The availability varies among different countries. Not all drugs are available in all countries. ${ }^{25}$ The oral treatment option includes different classes of hypoglycemic drugs. The selection of treatment agent is dependent upon the various factors and clinician decides the best suitable agent for the patient. Some drugs of different classes are combined together to achieve better result. The classes of oral hypoglycemic drugs include sulfonylurea, biguanides, thiozolidinediones, alpha glucosidase inhibitors, glinides, dipeptidyl peptidase 4 inhibitors, sodium glucose transporter 2 inhibitors. ${ }^{25}$ The injectable choices include amylin analogues, GLP1 receptor antagonist and insulin. Amylin analogues are also known as amyloid polypeptide analogues and includes pramlintide. The insulin has different types which includes short acting, intermediate acting and long acting insulin. Exenatide and liraglutide are GLP1 receptor blockers. Short acting insulin includes regular insulin, insulin aspart, insulin glusine and insulin lispro. Intermediate acting insulin includes isophane insulin and lente insulin while long acting insulin includes ultralente insulin, insulin detemir. ${ }^{25}$

\section{Pharmacokinetics and pharmacodynamics of vitamin C:}

The presence of vitamin $\mathrm{C}$ is an essential requirement for many enzymatic reactions to occur in all animals and plants and is made endogenously with the exception of humans. It is also known as ascorbate. Structurally it has six carbon lactone ring which is the building block for ascorbate. In humans it acts as a cofactor in many enzymatic reactions. It also empowers the defense mechanism by providing antioxidant activity. L-gluconolactone oxidase is an enzyme in the final step of the synthesis of ascorbic acid. Humans lack the ability to synthesize vitamin $\mathrm{C}$ as they are lacking this enzyme. So they depend on external sources of vitamin C. Diet is one of the important sources for intake of this vitamin. In diet fruits and vegetables are important sources while dairy products contain little amount of vitamin $\mathrm{C}$ and are the less important sources. The absorption of vitamin $\mathrm{C}$ is an important factor in favoring the antioxidant defense system. The absorption begins as soon as it enters the oral cavity and also gets absorbed as it passes through other parts of gastrointestinal system (GIT). Renal system is also involved in the metabolism of vitamin C. GIT is the major site for absorption of vitamin $\mathrm{C}$ with approximately $70 \%$ of vitamin $\mathrm{C}$ absorption. The recommended dietary allowance of vitamin $\mathrm{C}$ is $60 \mathrm{mg}$ per day. It has short half life and gets excreted from the body rapidly. The pharmacokinetic properties are enhanced by taking the vitamin $\mathrm{C}$ in higher doses greater than $1000 \mathrm{mg}$ per day. This produces enhanced bioavailability. Plasma Vitamin C levels are decreased in type 2 diabetes mellitus patients. ${ }^{26-28}$ Along with disease pathogenesis it also plays an important role in the lipid peroxidation. Decreased vitamin C levels will also increase the chances of CVS mortality and morbidity. ${ }^{29}$ Dietary sources are not much helpful as they contain less quantity of vitamin $C$ whereas repeated small doses of vitamin $C$ in the form of supplement are helpful. ${ }^{30}$ Due to the resemblance of vitamin $\mathrm{C}$ with glucose many reactions in the body are replaced and prevents glycosylation. ${ }^{31}$ In another study vitamin $C$ given in higher doses greater than $1000 \mathrm{mg} /$ day for six weeks helped in lowering the plasma sugar thereby achieving better insulin sensitivity. ${ }^{32}$ In a study by Harding et al. baseline vitamin $\mathrm{C}$ levels were inversely proportional to the fasting plasma glucose levels and lower plasma vitamin $\mathrm{C}$ levels were associated with increased risk of new onset type 2 diabetes mellitus. ${ }^{33}$ Vitamin $\mathrm{C}$ deficiency might also lead to increased synthesis of triglycerides by impairing the transport of long chain fatty acids. ${ }^{34}$ Researchers in the past have proposed that vitamin $\mathrm{C}$ given as supplement can reduce the cholesterol, triglycerides, lipid peroxidation and increase HDL-C and help in prevention of cardiovascular disease. ${ }^{17,35}$ Vitamin $\mathrm{C}$ is an electron donor and in this process it forms ascorbyl radical or semidehydroascorbic acid. This newly formed compound is relatively stable as compared to other free radicals and this enhanced stability make it better and preferable antioxidant. It is documented that vitamin $C$ is the only antioxidant in human plasma that helps in complete protection of endogenous lipids from oxidative damage caused by reactive oxygen species. ${ }^{36}$

\section{Interactive system of antioxidants:}

It has been advocated that vitamin $\mathrm{C}$ is involved in recycling of important antioxidant vitamins. Glutathione an important antioxidant is also recycled by vitamin C. Vitamin C functions along with glutathione as redox couple. Antioxidants interact with each other and may modulate the activity of many antioxidants and can help in diminishing oxidative stress. ${ }^{37}$

Vitamin C plays a role of leader among the anti oxidants. Vitamin $\mathrm{C}$ and other important antioxidant vitamins have been shown in several studies to be on the lower aspect in type 2 diabetes mellitus. Lower levels of other vitamins 
along with vitamin $\mathrm{C}$ are also implicated in the oxidative stress. ${ }^{38}$ Vitamin C efficacy on glycemic control has also been studied along with certain polyunsaturated fatty acids and has been advocated that vitamin $\mathrm{C}$ given in combination with these fatty acids can achieve better glycemic control and diminish the fasting blood glucose, lower the $\mathrm{HbAlc}$, low density lipoprotein cholesterol (LDL-C), triglycerides (TG) and increase the high density lipoprotein cholesterol (HDL-C).$^{39}$ Vitamin C given alone or in combination with other antioxidants can help in enzymatic transformation of superoxide anions into hydrogen peroxide in the mitochondria and hydrogen peroxide is removed by an enzyme glutathione peroxidase. When there is imbalance between production and breakdown of these superoxide radicals, the atherosclerosis and macro-vascular complications results. ${ }^{40}$ A meta-analysis has documented that vitamin $\mathrm{C}$ alone or in combination with other vitamins can raise the antioxidant capacity by elevating glutathione peroxidase activity, superoxide dismutase activity and total antioxidant capacity. ${ }^{41}$

\section{CONCLUSION:}

Vitamin $\mathrm{C}$ is one of the important antioxidant taken exogenously in the form of diet and supplement. It helps in controlling blood glucose level and helps in achieving good glycemic control in doses greater than $1000 \mathrm{mg}$ /day in divided doses as an adjunct to the treatment of type 2 diabetes mellitus. It also helps in reducing the levels of oxidative damage induced glycosylation of hemoglobin and lowers $\mathrm{HbAlc}$. In addition vitamin $\mathrm{C}$ has potential to reduce CVS induced complications and mortality in type $2 \mathrm{DM}$. Vitamin $\mathrm{C}$ causes reduction of lipid peroxidation and hence lowers the LDL-C, TG levels and raises the HDL-C. Thus vitamin $\mathrm{C}$ is a scavenger of free radicals that minimizes the complications associated with type 2 diabetes and improves the quality of life in patients suffering from this disease.

\section{REFERENCES:}

1. Dakhale GN, Chaudhari HV, Shrivastava M. Supplementation of vitamin $\mathrm{C}$ reduces blood glucose and improves glycosylated hemoglobin in type 2 diabetes mellitus: A randomized, doubleblind study. Adv Pharmacol Sci. 2011; DOI: 10.1155/2011 $/ 195271$.

2. Vinod K, Shete AN, Zingade US, Bansode DG. The effect of vitamin $\mathrm{C}$ on superoxide dismutase and blood sugar levels in patients of type 2 diabetes mellitus. International Journal of Health Sciences and Research 2014;4(10):94-100.

3. Carter P, Gray LJ, Talbot D, Morris DH, Khunti K, Davies MJ. Fruit and vegetable intake and the association with glucose parameters: A cross-sectional analysis of the Let's Prevent Diabetes Study. Eur J Clin Nutr. 2013;67(1):12-17.

4. Hegde SV, Adhikari P, Nandini M, DSouza V. Effect of daily supplementation of fruits on oxidative stress indices and glycemic status in type 2 diabetes mellitus. Complement Ther Clin Pract. 2013;19(2):97-100.

5. Wilson R, Willis J, Gearry R, Skidmore P, Fleming E, Frampton $\mathrm{C}$, et al. Inadequate vitamin $\mathrm{C}$ status in prediabetes and type 2 diabetes mellitus: Associations with glycemic control, obesity, and smoking. Nutrients. 2017;9(9):1-15.
6. Meo SA, Zia I, Bukhari IA, Arain SA. Type 2 diabetes mellitus in Pakistan: Current prevalence and future forecast. J Pak Med Assoc. 2016;66(12):1637-42.

7. Ali AE, Eman A, Ghfaar AE, Ghali AA, Zughbur MR, Sirdah MM. The effect of vitamin $\mathrm{C}$ and/or E supplementations on type 2 diabetic adult males under metformin treatment: A single-blinded randomized controlled clinical trial. Diab Met Syndr: Clin Res Rev 2018; https://doi.org/10.1016/j. dsx.2018.03.013.

8. Rachid E, Naoual E, Meryem L, Yahia C, Taoufik A, Driss $\mathrm{G}$ et al. Antioxidants status in type 2 diabetic patients in Morocco. Turkish Journal of Medical Sciences 2017;47:78288.

9. Jayesh KB, Sabin T, Nanjan MJ. Effect of oral supplementation of vitamin $\mathrm{C}$ on glycemic control and lipid profile in patients with type 2 diabetes mellitus. International Journal of Pharmacy and Pharmaceutical Sciences 2012;4(2):524-27.

10. Ashraf K, Khaldun MA. Effect of vitamin C on blood glucose and glycosylated hemoglobin in type II diabetes mellitus. World Journal of Analytical Chemistry 2015; 3(1A): 6-8.

11. Sushanta KD, Vijayakumar PRA, Senthil R, Jayesh KB, Gupta $\mathrm{S}$. Antioxidant effect of vitamin $\mathrm{C}$ on type 2 diabetes mellitus patients along with two different oral hypoglycemic agents for smooth glycemic control . World Journal of Pharmacy and Pharmaceutical Sciences 2012;1(3):1113-22.

12. Zahra R, Atena S, Shahin A, Rokia MY. Association of dietary vitamin $C$ and $E$ intake and antioxidant enzymes in type 2 diabetes mellitus. Global Journal of Health Science 2013;5(3):183-87.

13. Mohammed SE, Asmah R, Ismail P, Huzwah K, Yehia A . Effect of vitamin $\mathrm{C}$ on inflammation and metabolic markers in hypertensive and/or diabetic obese adults: a randomized clinical trial. Drug Design, Development and Therapy 2015;9:3405-12.

14. Zohreh M, Najmeh H, Mohammed HD, Hamid RT, Afsane A, Hasti A. Effect of vitamin C supplementation on postprandial oxidative stress and lipid profile in type 2 diabetic patients. Pakistan Journal of Biological Sciences 2011;14(19):900-04.

15. Okafor HK, Ofoegbu AC, Nlebedim AO. Oral hypoglycemic agent and Ascorbic acid supplementation therapy synergistically ameliorates blood glucose, serum lipid and inflammatory response in type 2 diabetes mellitus patients. J Anal Pharm Res 2016; 3(4): DOI:.

16. Akram TK, Hisham MD. Diabetes mellitus: The epidemic of the century. World J Diabetes 2015;6(6):850-67.

17. Sanguanwong S, Tangvarasittichai O, Sengsuk C, Tangvarasittichai $\mathrm{S}$. Oral supplementation of vitamin $\mathrm{C}$ reduced lipid peroxidation and insulin resistance in patients with type 2 diabetes mellitus. International Journal of Toxicological and Pharmacological Research 2016;8(3):114-19.

18. Ozra TM, Shekoufeh N, Bagher L, Mohammad A. Influence of ascorbic acid supplementation on type 2 Diabetes Mellitus in observational and randomized controlled trials; A systematic review with meta-analysis. J Pharm Pharm Sci 2014;17(4):55482.

19. Ashor AW, Werner AD, Lara J, Willis ND, Mathers JC, Siervo M. Effects of vitamin C supplementation on glycaemic control: a systematic review and meta-analysis of randomised controlled trials. Eur J Clin Nutr 2017;71(12):1371-80. 
20. Rekha N, Bhagya MS. Comparison of efficacy and tolerability of vitamin $\mathrm{C}$ as add on therapy to the oral hypoglycaemic agent in newly diagnosed type 2 Diabetes Mellitus. International Journal of Drug Development and Research 2013;5(2):187-94.

21. Shaun AM, Paul ADG, Rod JS, Aaron PR, Glenn DW. Ascorbic acid supplementation improves skeletal muscle oxidative stress and insulin sensitivity in people with Type 2 diabetes: findings of a randomized controlled study. Free Radical Biology and Medicine 2016;93:227-38.

22. Konstantinos P, Nikolaos P, Maciej B, Dimitrios P, Michael E. Complications of Diabetes 2016. Journal of Diabetes Research 2016. DOI: 10.1155/2016/6989453

23. Omolola RA, Nicole LB, Oluwafemi OO. Oxidative stress and diabetic complications: The role of antioxidant vitamins and flavonoids. Oluwafemi Oguntibeju (ed). Antioxidant antidiabetic agents and human health. : InTech; 2014. pp. 2558. DOI: $10.5772 / 57029$

24. Amin TH, Sherin MAZ, Ashraf AS. The effect of vitamin C alone or in combination with vitamin $\mathrm{E}$ on fasting blood glucose, glycosylated hemoglobin and lipid profile in type 2 diabetic patients (Gaza strip). Jordan Journal of Pharmaceutical Sciences 2016; 9(1).

25. Steven EK, Mark EC, Stefano DP. Pathophysiology and treatment of type 2 diabetes: perspectives on the past, present and future. Lancet 2014;383(9922):1068-83.

26. Santosh HN, David CM. Role of ascorbic acid in diabetes mellitus: a comprehensive review. Journal of Medicine, Radiology, Pathology \& Surgery 2017;4:1-3.

27. Wilson R, Willis J, Gearry R, Skidmore P, Fleming E, Frampton $\mathrm{C}$, et al. Inadequate vitamin $\mathrm{C}$ status in prediabetes and type 2 diabetes mellitus: Associations with glycemic control, obesity, and smoking. Nutrients. 2017;9(9):1-15.

28. Shailaza S, Rahul R. Comparison of Vitamin C status in type 2 diabetic patients and normal controls. International Journal of Scientific Research 2013;2(12):417-18.

29. Lamb MJE, Griffin SJ, Sharp SJ, Cooper AJM. Fruit and vegetable intake and cardiovascular risk factors in people with newly diagnosed type 2 diabetes. European Journal of Clinical Nutrition 2017;71:115-21.

30. Parisa G, Mehdi N, Alireza G, Foad R. The effects of vitamin c on diabetic patients. Der Pharmacia Lettre 2015;7(10):6871.

31. Kathore VR, Bansode DG. The effect of vitamin C on fasting blood glucose level and lipid profile in type 2 diabetes meliitus patients. International Journal of Recent Trends in Science And Technology 2015;16(3):585-90.
32. Shaun AM, Bodil R, Luc JCL, Jo S, Glenn DW. Ascorbic acid supplementation improves postprandial glycaemic control and blood pressure in people with type 2 diabetes: Findings of a randomized cross-over trial. Diabetes Obes Metab 2018;DOI: 10.1111/dom.13571

33. Harding AH, Wareham NJ, Bingham SA, Khaw K, Luben R, Welch A et al.. Plasma vitamin C level, fruit and vegetable consumption, and the risk of new-onset type 2 diabetes mellitus: the European prospective investigation of cancer-Norfolk prospective study. Arch Intern Med 2008;168(14):1493-99.

34. Syed WG, Syed ASS, Mohi IMA, Mirza RB. Combined effect of metformin with ascorbic acid versus acetyl salicylic acid on diabetes-related cardiovascular complication; a 12-month single blind multicenter randomized control trial. Cardiovascular Diabetology 2017;16(103). DOI: 10.1186/s12933-017-0584-9

35. Rajneesh P, Ijen B, Anupam J. Combined effect of vitamin $\mathrm{C}$ and $\mathrm{E}$ dose on Type 2 diabetes patients. Advances in Diabetes and Metabolism 2017;5(2):21-25.

36. Chunling Z, Lixin N, Ruiqi S, Yu C, Ying L, Xiaoyan W et al. Dietary vitamin $C$ intake reduces the risk of Type 2 diabetes in Chinese adults: HOMA-IR and T-AOC as potential mediators. PLoS ONE 2016;11(9). DOI:

37. Daniel MT, Abdelouahed K, Lise T, Tamas F. Effects of vitamin $\mathrm{C}$ supplementation on antioxidants and lipid peroxidation markers in elderly subjects with type 2 diabetes. Archives of Gerontology and Geriatrics 2009;48:67-72.

38. Mohammad RM, Masoud K, Yadollah M. The effects of omega-3 plus vitamin $\mathrm{E}$ and zinc plus vitamin $\mathrm{C}$ supplementation on cardiovascular risk markers in postmenopausal women with type 2 diabetes. Therapeutic Advances in Endocrinology and Metabolism 2014;5(4):6776.

39. Mohammad MSM, Mahmoud D, Seyed AD, Seyed AK, Mohammed RE, Ali ASY et al. Effects of eicosapentaenoic acid and vitamin $\mathrm{C}$ on glycemic indices, blood pressure, and serum lipids in type 2 diabetic Iranian males. J Res Med Sci 2011;16(Supp11):S361-Ss67.

40. Mohammad RM, Masoud K, Yadollah M. Effect of EPA and vitamin $\mathrm{C}$ on superoxide dismutase, glutathione peroxidase, total antioxidant capacity and malondialdehyde in Type 2 diabetic patients. Oman Medical Journal 2014;29(1):39-45.

41. Maria EB, Fernanda ST, Antonio MM, Helena HB, Astrid W, Fernando FL et al. Antioxidant effects of vitamins in type 2 diabetes: a meta-analysis of randomized controlled trials. Diabetol Metab Syndr. 2018;10(18). 